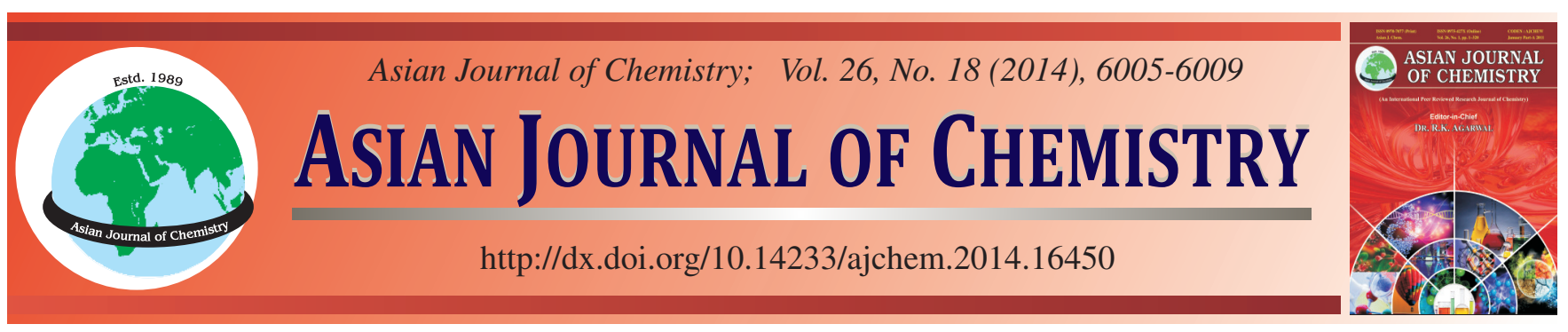

\title{
Physico-Chemical Properties of Organic Nonlinear Optical Crystal for Frequency Doubling: Morpholinium Hydrogen Tartrate
}

\author{
R. Renugadevi ${ }^{1}$ and R. Kesavasamy ${ }^{2, *}$
}

${ }^{1}$ Department of Physics, Sri Guru Institute of Technology, Coimbatore-641 110, India

${ }^{2}$ Department of Physics, Sri Ramakrishna Engineering College, Coimbatore-641 020, India

*Corresponding author: E-mail: kesav_cbe@yahoo.co.in

Published online: 1 September 2014;

AJC-15842

\begin{abstract}
Nonlinear optical crystal of morpholinium hydrogen tartrate have been synthesized and grown in aqueous solution by slow evaporation technique. The cell parameters of the grown crystal is identified by single crystal X-ray diffraction analysis which confirms that the morpholinium hydrogen tartrate crystallizes in orthorhombic system with noncentro symmetric space group. The powder X-ray diffraction pattern of the grown crystal has been indexed. FT-IR spectrum was recorded to identify the various functional groups of morpholinium hydrogen tartrate. The various kinds of protons and carbons of morpholinium hydrogen tartrate have been identified using ${ }^{1} \mathrm{H}$ and ${ }^{13} \mathrm{C}$ NMR spectral analyses. The range of optical absorption was ascertained by recording UV-visible NIR spectral studies. The TG/DTA studies of the grown crystal has been revealed. The mechanical property of the grown crystal was analyzed using Vickers microhardness studies. The nonlinear optical crystal activity of the crystal is confirmed by Kurtz-Perry powder technique.
\end{abstract}

Keywords: Nonlinear optical material, Crystal growth, X-ray diffraction, Thermal analysis.

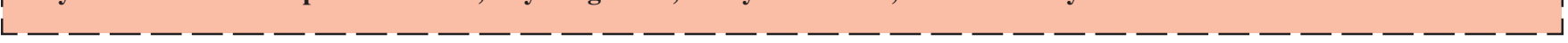

\section{INTRODUCTION}

In recent years, organic nonlinear optical materials have been actively studied for their use in nonlinear optics and devices. The search for efficient nonlinear optical crystals has been greatly investigated, in fact, that search for the "polar crystals" in which the macroscopic properties reflect the internal asymmetric molecular relationships. The organic nonlinear optical crystals provide the key functions of frequency conversion and optical switching, may also plays an important role in telecommunication, optical data storage, optical information processing, electro-optic modulation, degenerate four wave mixing, colour display, medical diagnostic and second harmonic generation ${ }^{1,2}$.

Frequency doubling crystals are crucial components in many laser systems. Generally, nonlinear optical crystals require high conversion efficiencies, transparent in visible and ultraviolet ranges for numerous device applications. Within the last few years, much progress has been made in the development of nonlinear optical organic materials for second harmonic generation. However, most of the organic nonlinear optical crystal crystals are constituted by weak van der Waals and hydrogen bonds with conjugated $\pi$ electrons ${ }^{3}$.

Morpholine is a strong alkali, which can be considered as a kind of secondary aliphatic amine. However, the incorporation of nitrogen into the six-member ring exposes the lone electron pair on nitrogen and makes the molecule as a good nucleophile. Morpholine and its derivatives are known to form a series of molecular complexes such as morpholine ${ }^{4}$, hydro halides ${ }^{5}$, phenols $^{6}$ and phosphoric acid ${ }^{7}$. Recently, the structure and various characterizations of nonlinear optical crystal of morpholinium 4-aminobenzoate have been reported ${ }^{8}$. The tartaric acid forms a broad family of hydrogen-bonded crystals. The studies of molecular packing and hydrogen bonding in tartaric acid and its derivatives are relevant to the development in crystal engineering ${ }^{9-11}$. Some of the reported promising nonlinear optical crystal tartrate derivatives are L-alaninium tartrate $^{12}$, L-prolinium tartrate ${ }^{13}$, melaminium L-tartrate monohydrate ${ }^{14}, p$-nitroaniline L-tartrate ${ }^{15}$, D-tartaric acidnicotinamide ${ }^{16}$ and anilinium D-tartrate ${ }^{17}$ crystallize in noncentrosymmetric structure and exhibit second order nonlinear optical properties.

The crystal structure of morpholinium hydrogen tartrate was reported by Liu et al. ${ }^{18}$. The crystal complex was formed by the transformation of one proton of the L-tartaric acid to the nitrogen atom of morpholine.

\section{EXPERIMENTAL}

Synthesis and crystal growth: Morpholinium hydrogen tartarate single crystals were synthesized from morpholine (Merck GR grade) and L-tartaric acid. The calculated amount 
of morpholine dissolved in ethanol and required amount of L-tartaric acid was added to this by continuous stirring. A homogeneous aqueous solution of morpholinium hydrogen tartarate was prepared by mixing of morpholine with saturated solution of L-tartaric acid. The reaction was exothermic and some white fumes were observed, the turbid white solution of the acid turned to yellow on addition of the colorless morpholine and the preparative solution temperature became $45^{\circ} \mathrm{C}$. To make the homogeneous solution, it was continuously stirred well for about $6 \mathrm{~h}$ and then evaporated to dryness. The dried salt was collected for further growth of morpholinium hydrogen tartrate. The synthesized compound was further improved by successive recrystallization process. The reaction scheme is depicted in Fig. 1.<smiles>O=C(O)C(O)C(O)C(=O)OCCN1CCOCC1</smiles>

Fig. 1. Reaction scheme for morpholinium hydrogen tartrate

The solubility was measured by taking excess amount of morpholinium hydrogen tartrate in the solvent and it is continuously stirred to achieve uniform concentration over the entire volume of the solution. The solubility was determined for different temperatures $\left(25-45^{\circ} \mathrm{C}\right)$ with the interval of $5{ }^{\circ} \mathrm{C}$. After attaining the saturation, the concentration of the solute was estimated gravimetrically. The studies were carried out in a constant temperature bath with a cryostat facility with an accuracy of $\pm 0.01 \mathrm{~K}$. It is observed that morpholinium hydrogen tartrate is moderately soluble in water. The solubility almost increases linearly with the increase of temperature.

The prepared solution was filtered off using Whatmann filter paper to remove the suspended impurities. The saturated solution with perforated cover was maintained in an undisturbed condition. Single crystals of morpholinium hydrogen tartrate were grown from the supersaturation solution at room temperature. The solution was periodically inspected and after 30 days of growth period, good quality single crystals of morpholinium hydrogen tartrate have been harvested with maximum size up to $7 \mathrm{~mm} \times 8 \mathrm{~mm} \times 2 \mathrm{~mm}$.

\section{RESULTS AND DISCUSSION}

Single crystal and powder $\mathrm{X}$-ray diffraction studies: Single crystal X-ray diffraction study was carried out using a Bruker Axs (Kappa Apex II) diffractometer with MoK $\alpha$ $(0.71073 \AA)$ radiation at room temperature. The estimated cell parameters of morpholinium hydrogen tartrate crystals are, a $=7.24 \AA, b=9.04 \AA, c=16.20 \AA$ and $\mathrm{V}=1064 \AA^{3}$. The morpholinium hydrogen tartrate crystal belongs to orthorhombic system with the space group of $\mathrm{P} 2{ }_{1} 2_{1} 2_{1}$. It is observed that lattice parameter values of morpholinium hydrogen tartrate are in good agreement with the reported values ${ }^{18}$. The powder form of the grown crystal was subjected to powder X-ray diffraction analysis. The scan was performed over the range $10-35^{\circ}$, in steps of $0.02^{\circ}$ by employing BRUKER (D8 Advance). The obtained $2 \theta$ values are used for indexing using the 'TWOTHETA' software. The obtained diffraction peaks shows that the good crystalline nature of grown crystal. The powder X-ray diffraction pattern is shown in Fig. 2.

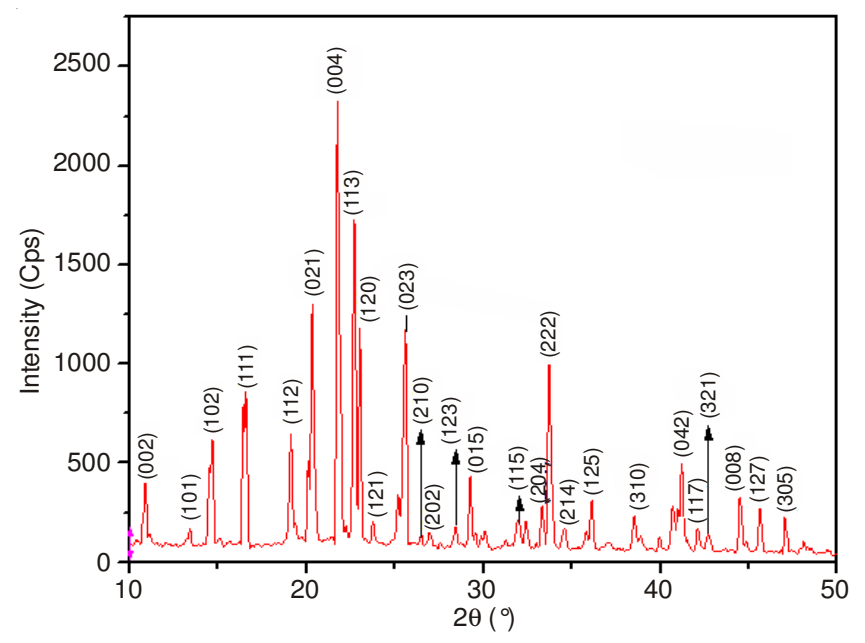

Fig. 2. Powder XRD pattern of morpholinium hydrogen tartrate

Fourier transform infrared analysis: The FT-IR spectrum of the crystal was recorded using $\mathrm{KBr}$ pellet technique in the frequency region of 400-4000 $\mathrm{cm}^{-1}$ using a JASCO FT-IR spectrometer. The FT-IR spectrum of morpholinium hydrogen tartrate is shown in Fig. 3. A strong band observed at 3510 $\mathrm{cm}^{-1}$ is assigned to free $\mathrm{OH}$ stretching vibrations. The characteristic absorption peaks at 3419 and $3310 \mathrm{~cm}^{-1}$ are assigned to $\mathrm{NH}_{2}{ }^{+}$asymmetric and symmetric stretching vibrations respectively. The intense peaks at 3030 and $2990 \mathrm{~cm}^{-1}$ are due to asymmetric and symmetric $\mathrm{CH}$ stretching vibrations. The sharp peaks at 2504 and $2443 \mathrm{~cm}^{-1}$ are due to the overtones and combinations. The $\mathrm{C}=\mathrm{O}$ stretching vibration occurred at $1722 \mathrm{~cm}^{-1}$. The peak at $1570 \mathrm{~cm}^{-1}$ is assigned for the $\mathrm{NH}_{2}$ bending vibration. The symmetric and asymmetric $\mathrm{COO}^{-}$vibrations produced peaks at 1407 and $1563 \mathrm{~cm}^{-1}$ respectively. The absorptions peaks at 1167 and $1098 \mathrm{~cm}^{-1}$ are due to the asymmetric and symmetric stretching vibration of C-O-C group respectively. From FT-IR spectrum, the observed IR frequencies and their corresponding assignments are shown in Table-1.

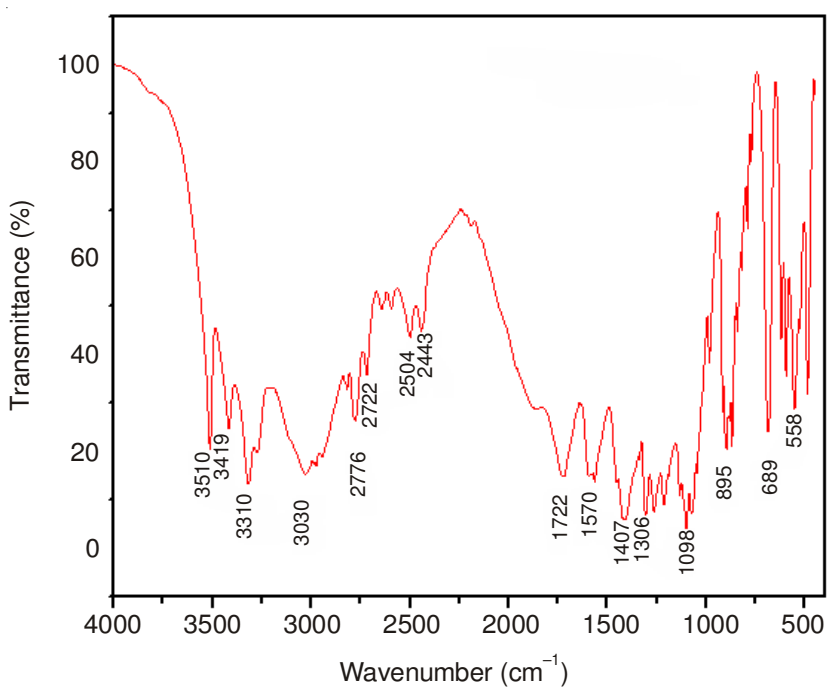

Fig. 3. FT-IR spectrum of morpholinium hydrogen tartrate 


\begin{tabular}{cl} 
TABLE-1 \\
FT-IR SPECTRAL DATA OF \\
MORPHOLINIUM HYDROGEN TARTRATE \\
\hline Wave number $\left(\mathrm{cm}^{-1}\right)$ & \multicolumn{1}{c}{ Tentative assignments } \\
\hline 3510 & $\mathrm{O}^{-} \mathrm{H}^{+}$stretching \\
3419 & $\mathrm{NH}_{2}{ }^{+}$asymmetric stretching \\
3310 & $\mathrm{NH}_{2}^{+}$symmetric stretching \\
3030 & Asymmetric $\mathrm{C}-\mathrm{H}$ stretching \\
2990 & Symmetric $\mathrm{C}-\mathrm{H}$ stretching \\
1722 & $\mathrm{C}=\mathrm{O}_{\text {stretching }}$ \\
1570 & $\mathrm{NH}_{2}$ bending \\
1407 & Symmetric COO vibrations \\
1563 & Asymmetric COO vibrations \\
1167 & Asymmetric C-O-C stretching \\
1098 & Symmetric C-O-C stretching \\
\hline
\end{tabular}

Nuclear magnetic resonance studies: In the present investigation, ${ }^{1} \mathrm{H}$ NMR and ${ }^{13} \mathrm{C}$ NMR spectra of the morpholinium hydrogen tartrate have been recorded with a JEOLGSX 4000 NMR spectrometer operating at $400 \mathrm{MHz}$ with $\mathrm{D}_{2} \mathrm{O}$ as a solvent. The ${ }^{1} \mathrm{H}$ NMR spectrum of morpholinium hydrogen tartrate is shown in Fig. 4a. In proton NMR, the signal appears at $\delta=4.2 \mathrm{ppm}$ is due to $\mathrm{CH}$ (a) of tartaric acid ( $2 \mathrm{H}$, Doublet). The triplet signal at $\delta=3.8 \mathrm{ppm}$ and $\delta=3.2$ ppm is assigned to the $\mathrm{CH}_{2}$ (b and c) protons of morpholinium cation.

The ${ }^{13} \mathrm{C}$ NMR spectrum of morpholinium hydrogen tartrate is shown in Fig. 4b. The assignment of each signal to a unique carbon environment molecule is also indicated. The ${ }^{13} \mathrm{C}$ NMR spectrum consists of 4 signals. The signals at $\delta=$ $43.21 \mathrm{ppm}$ and at $\delta=63.58 \mathrm{ppm}$ are assigned for carbons of morpholine, respectively. The presence of signal at $\delta=176.267$ $\mathrm{ppm}$ is due to the carbonyl carbon of $\mathrm{COOH} / \mathrm{COO}^{-}$of tartaric acid. Similarly, the resonance signal at $\delta=72.751 \mathrm{ppm}$ is attributed to the $\mathrm{CH}$ of tartaric acid.

Optical transmission spectral studies: The transmission spectrum of morpholinium hydrogen tartrate was recorded in the wavelength range 200 to $1100 \mathrm{~nm}$ using PerkinElmer Lambda35 spectrometer (Fig. 5a). The spectrum gives information about the structure of molecules, because the absorption of UV and visible light involves promotion of the electron in the $\mathrm{s}$ and $p$ orbital from the ground state to higher states ${ }^{19}$. The morpholinium hydrogen tartrate crystal is active in the UVvisible region and the compound material could be a viable alternative for optical material in the entire visible region. It
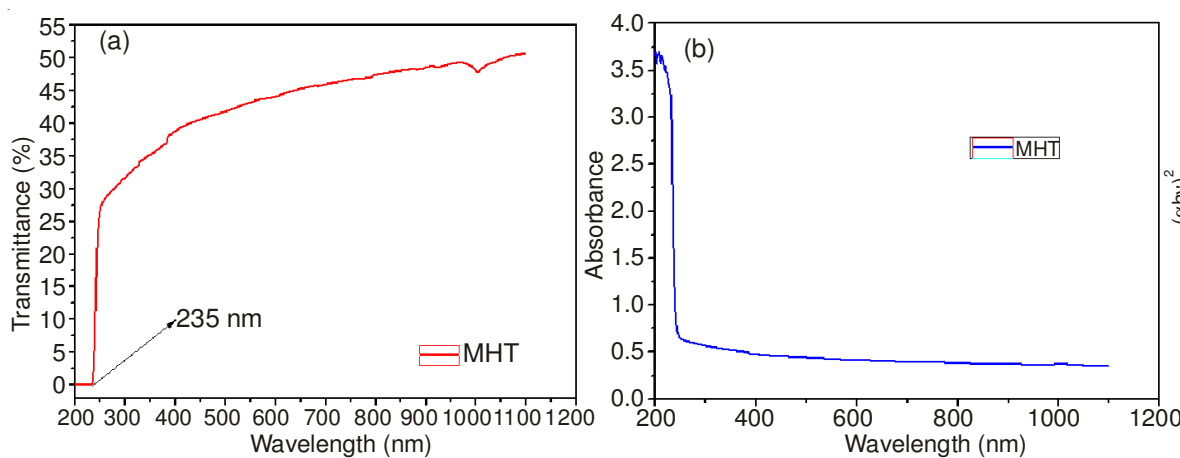

Fig. 5. (a) UV-visible-NIR transmittance spectrum; (b) Absorbance spectrum of morpholinium hydrogen tartrate; (c) Plot of ( $\alpha$ hv) ${ }^{2} v s$. photon energy of morpholinium hydrogen tartrate

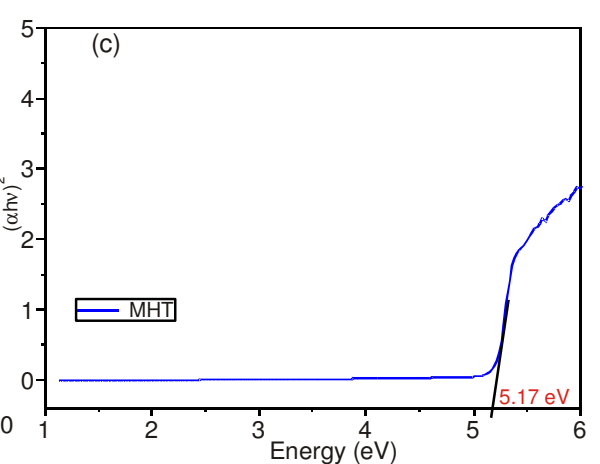

has good transparency of about $51 \%$ with a cutoff wavelength of $235 \mathrm{~nm}$. The observed nature of absorption in the visible

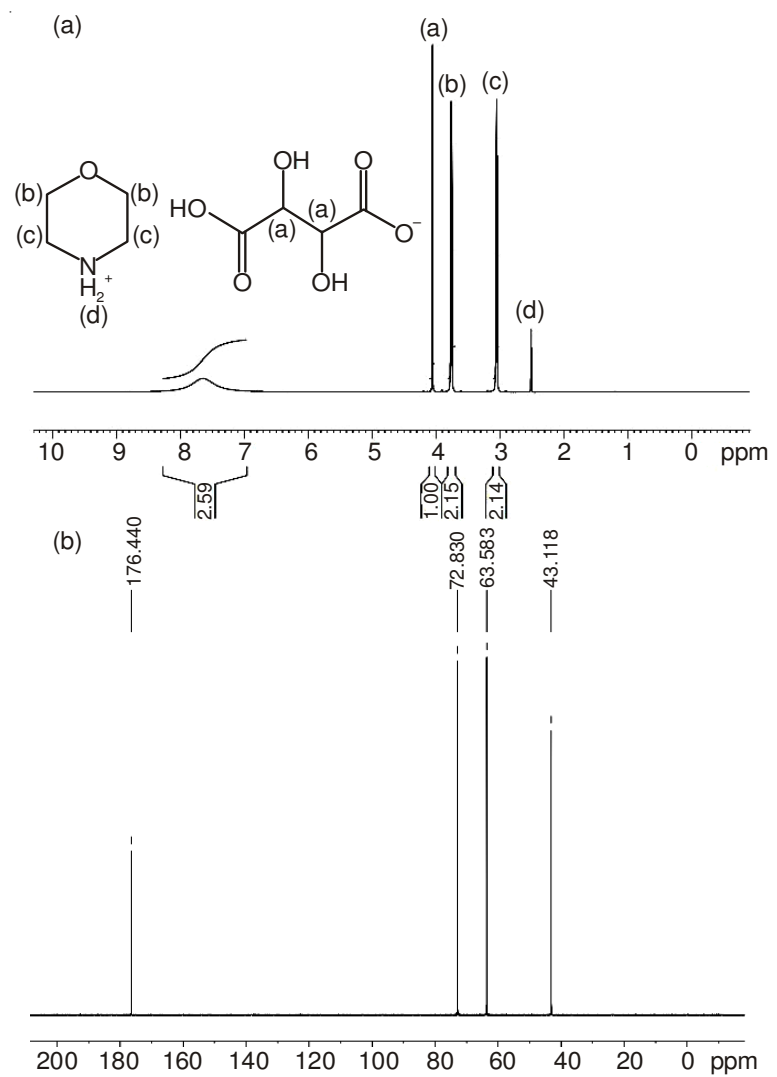

Fig. 4. (a) ${ }^{1} \mathrm{H}$ NMR spectrum of morpholinium hydrogen tartrate; (b) ${ }^{13} \mathrm{C}$ NMR spectrum of morpholinium hydrogen tartrate

region is a desirable property for nonlinear optical crystal applications. The absorption spectrum of morpholinium hydrogen tartrate crystal is shown in Fig. 5b. The optical absorption coefficient $(\alpha)$ was calculated using the relation:

$$
\alpha=2.3026(1 / \mathrm{T}) / \mathrm{t}
$$

where $\mathrm{T}$ is the transmittance and $\mathrm{t}$ is thickness of the crystal.

Optical band gap $\left(\mathrm{E}_{\mathrm{g}}\right)$ was evaluated from the transmission spectra and optical absorption coefficient $(\alpha)$ near the absorption edge is given $b^{20}$ :

$$
(\alpha h v)^{2}=\mathrm{A}\left(\mathrm{h} v-\mathrm{E}_{\mathrm{g}}\right)
$$

where $\mathrm{A}$ is a constant, $\mathrm{E}_{\mathrm{g}}$ is the optical band gap, $\mathrm{h}$ is the Planck constant and $v$ is the frequency of the incident photons. The 
band gap of morpholinium hydrogen tartrate crystal was estimated by plotting $(\alpha h v)^{2}$ versus $h v$ which is shown in Fig. $5 \mathrm{c}$ and extrapolating the linear portion near the onset of absorption edge to the energy axis. From the Figure, the value of band gap was found to be $5.17 \mathrm{eV}$. Some properties of organic nonlinear optical crystals are listed in Table-2.

\begin{tabular}{|c|c|c|c|c|}
\hline \multicolumn{5}{|c|}{$\begin{array}{c}\text { TABLE-2 } \\
\text { SHG EFFICIENCIES, TRANSPARENCY AND CUTOFF } \\
\text { WAVE LENGTH OF SOME ORGANIC NONLINEAR } \\
\text { OPTICAL CRYSTALS }\end{array}$} \\
\hline Crystals & $\begin{array}{c}\text { Optical } \\
\text { transm- } \\
\text { ission (\%) }\end{array}$ & $\begin{array}{l}\text { Transpa- } \\
\text { rency cut } \\
\text { off (nm) }\end{array}$ & $\begin{array}{c}\text { SHG } \\
\text { efficiency } \\
\text { KDP=1 }\end{array}$ & Ref. \\
\hline $\begin{array}{l}\text { Picolinium tartarate } \\
\text { monohydrate }\end{array}$ & 70 & 295 & 0.5 & {$[21]$} \\
\hline Picolinium maleate & 42 & 325 & 0.4 & {$[22]$} \\
\hline $\begin{array}{l}\text { 2-Carboxy } \\
\text { pyridinium tartarate }\end{array}$ & 44 & 300 & 0.75 & {$[23]$} \\
\hline $\begin{array}{l}\text { L-prolinium } \\
\text { trichloroacetate }\end{array}$ & 38 & 260 & Half of KDP & [24] \\
\hline Ammonium malate & 34 & 210 & 2 & [25] \\
\hline $\begin{array}{l}\text { Morpholinium } \\
\text { hydrogen tartrate }\end{array}$ & 51 & 235 & 1.16 & $\begin{array}{c}\text { Present } \\
\text { work }\end{array}$ \\
\hline
\end{tabular}

Thermal studies: Thermal studies were carried out using NETZSCH-Geratebau STA 409 PC thermal analyzer. The experiment was performed in a nitrogen atmosphere. In order to find out the thermal stability and decomposition steps of morpholinium hydrogen tartrate, $5.86 \mathrm{mg}$ of powdered sample was taken for TG/DTA studies and the corresponding thermograms are shown in Fig. 6. The DTA trace indicating endothermic starting at about $170.86^{\circ} \mathrm{C}$ indicates the good degree of crystallinity and melting point of the morpholinium hydrogen tartrate compound and the second endothermic peak starting at 191.85 ${ }^{\circ} \mathrm{C}$ is due to the decomposition of the compound. From the TGA trace, it was found that the material is stable up to $159.26^{\circ} \mathrm{C}$ and weight loss occurred drastically up to $239.64{ }^{\circ} \mathrm{C}$ due to the complete decomposition of the material. From the thermal analyzes, the crystal is found to stable up to the temperature $159.26^{\circ} \mathrm{C}$. Hence the material can be exploited for any suitable application up to $159.26^{\circ} \mathrm{C}$.

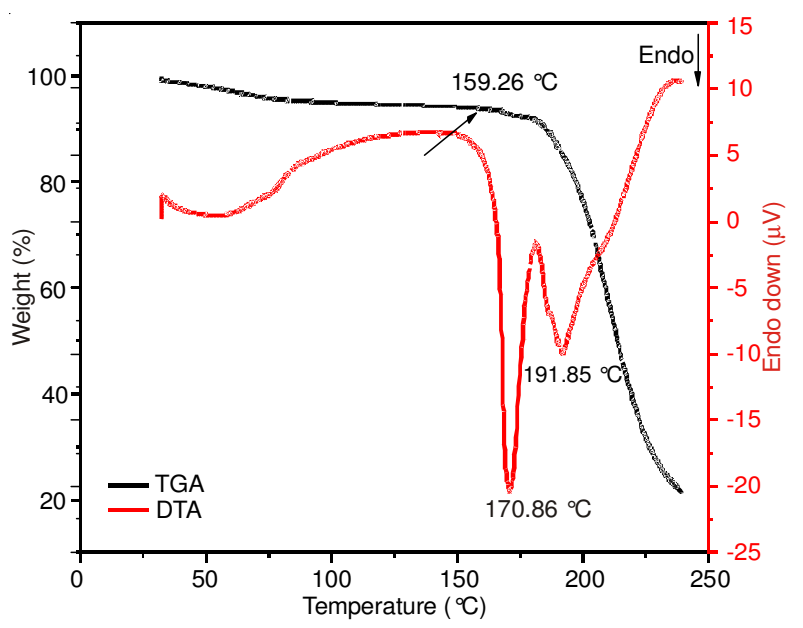

Fig. 6. TG/DTA curve of morpholinium hydrogen tartrate

Microhardness studies: The structure and molecular composition are greatly influence the mechanical properties of crystals. Microhardness measurement was carried out on as- grown flat face of morpholinium hydrogen tartrate crystal using LEITZ WETZLER hardness tester fitted with a Vickers' diamond indenter. Hardness of the material is a measure of the resistance it offers to local deformation ${ }^{26}$. Vickers hardness number $\mathrm{H}_{\mathrm{v}}$ was calculated from the following relation,

$$
\mathrm{H}_{\mathrm{v}}=1.8554\left(\mathrm{P} / \mathrm{d}^{2}\right) \mathrm{kg} / \mathrm{mm}^{2}
$$

where $\mathrm{H}_{\mathrm{v}}$ is the hardness number, $\mathrm{P}$ is the applied load and $\mathrm{d}$ is the diagonal length measured in micrometer. The variation of load is ranging from 1 to $100 \mathrm{~g}$. Fig. 7a shows the variation of hardness number with load. A hardness number increase with an increase in applied load is called reverse indentation size effect ${ }^{27}$. The crystal is stable up to $100 \mathrm{~g}$. On further increasing rearrangement of dislocations and their mutual interaction increases resulting in saturation of hardness or load independent hardness ${ }^{28}$. The plot of $\log \mathrm{P}$ against $\log \mathrm{d}$ is a straight line shown in Fig. 7b, which is in good agreement with Meyer's relation $\mathrm{P}=\mathrm{k}_{1} \mathrm{~d}^{\mathrm{n} 29}$ where $\mathrm{k}_{1}$ is material's constant and ' $\mathrm{n}$ ' is the Meyer's index or work hardening coefficient. The slope of the graph gives ' $n$ ' value and it was found 3.1. According to Onitsch theory ${ }^{30}$, if $n$ value is less than 1.6 , the materials are said to be harder one. If $\mathrm{n}$ value is greater than 1.6, the materials are said to be softer one. Hence morpholinium hydrogen tartrate crystal belongs to soft material category.
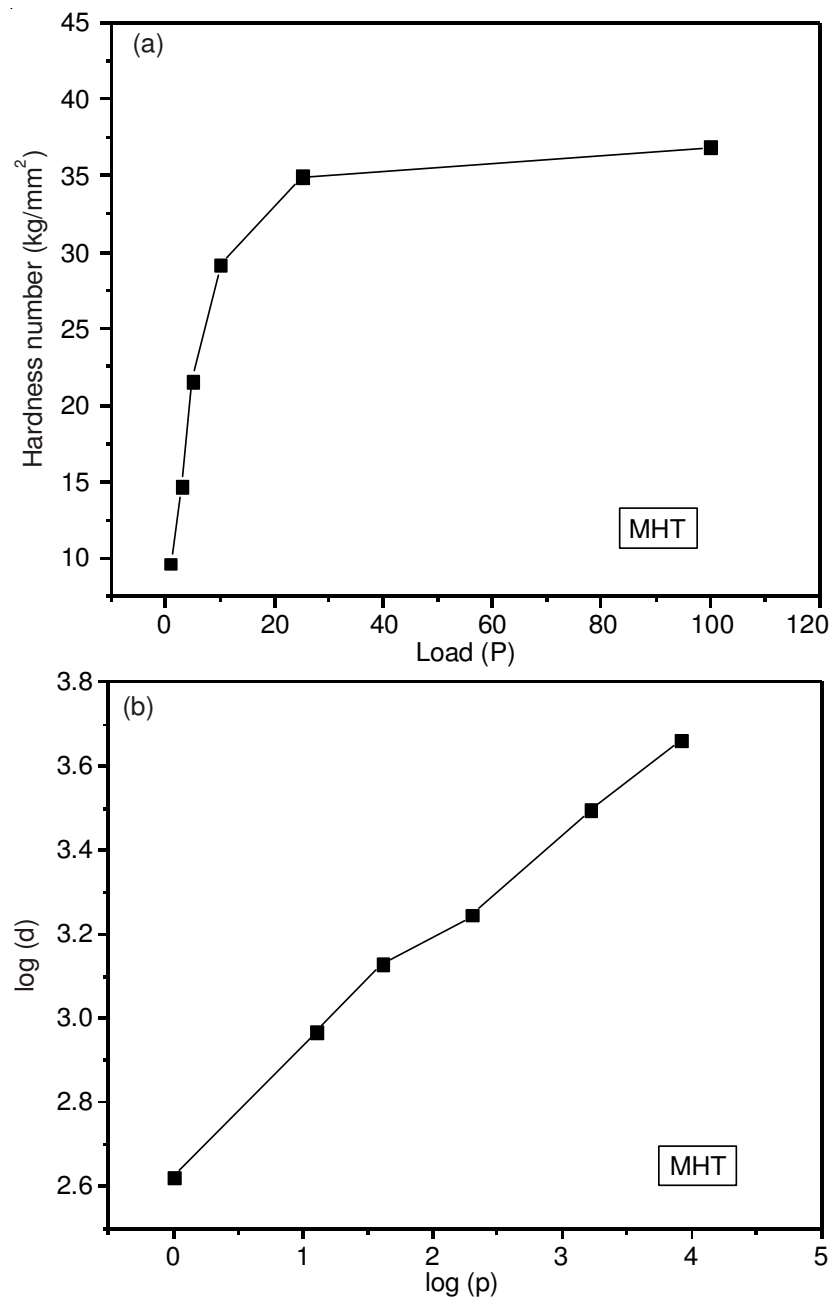

Fig. 9. (a) Variation of micro hardness number with load; (b) $\log$ (p) vs. $\log (d)$ 
Nonlinear optical studies: Kurtz and Perry powder method $^{31}$ was employed to check the SHG efficiency of morpholinium hydrogen tartrate crystal. The crystalline sample was powdered to uniform particle size around $160 \mu \mathrm{m}$ packed in a micro capillary of uniform bore and was exposed to Qswitched Nd: YAG laser operating at $1064 \mathrm{~nm}$ radiation with $10 \mathrm{~ns}$. The generation of second harmonic was confirmed by the emission of green light. Micro-crystalline material of KDP was used to compare with morpholinium hydrogen tartrate for second harmonic generation experiment. The relative SHG efficiency of grown crystal was found to be 1.16 times higher than that of KDP crystal.

\section{Conclusion}

A potential organic nonlinear optical crystal material morpholinium hydrogen tartrate were grown from slow evaporation solution technique. Single crystal X-ray diffraction analysis revealed that the compound crystallizes in orthorhombic system with non-centrosymmetric space group $\mathrm{P} 2{ }_{1} 2_{1} 2_{1}$. The powder X-ray diffraction have been taken to confirm the formation of the material. Vibrational spectral analysis confirms the presence of all the functional groups present in the sample. The presence of carbons and protons were confirmed by ${ }^{1} \mathrm{H}$ and ${ }^{13} \mathrm{C}$ NMR analyses. The UV-visible NIR spectrum establishes that the crystal acts as a good transmittance window and allows for frequency conversion down to UV region. From the thermal studies, it is concluded that the crystal is stable up to $159.26{ }^{\circ} \mathrm{C}$. Microhardness study revealed that the material belongs to soft material category. Kurtz and Perry powder experiment confirm the SHG using $\mathrm{Nd}$ : YAG laser and conversion efficiency is 1.16 times higher than that of the standard KDP crystal.

\section{ACKNOWLEDGEMENTS}

The author thanks the Management, Principal and Head of the Department of Science and Humanities, Sri Guru Institute of Technology, Coimbatore for their encouragement and everlasting support. The authors are also thankful to SAIF, IIT Madras for the characterization studies.

\section{REFERENCES}

1. D.S. Chemla and J. Zyss, Nonlinear Optical Properties of Organic Molecules and Crystals, Vol. 1, Academic Press, London (1987).

2. J. Badan, R. Hierle, A. Perigand and J. Zyss, In: Williams (Ed), Nonlinear Optical Properties of Organic molecules and Polymeric Materials, Am. Chem. Soc., Washington, DC, Vol. 233, p. D5 (1993).

3. D. Xu, M. Jiang and Z.Tan, Acta Chim. Sin., 41, 570 (1983).

4. A. Parkin, I.D.H. Oswald and S. Parsons, Acta Crystallogr. B, 60, 219 (2004).

5. Z. Dega-Szafran, I. Gaszczyk, D. Maciejewska, M. Szafran, E. Tykarska and I. Wawer, J. Mol. Struct., 560, 261 (2001).

6. I. Majerz, E. Kwiatkowska and A. Koll, J. Mol. Struct., 831, 106 (2007).

7. H. Ratajczak, J. Baran, J. Barycki, S. Debrus, M. May, A. Pietraszko, H.M. Ratajczak, A. Tramer and J. Venturini, J. Mol. Struct., 555, 149 (2000).

8. C.B. Aakeroy, P.B. Hitchcock and K.R. Seddon, J. Chem. Soc. Chem. Commun., 7, 553 (1992).

9. C.B. Aakeroy and K.R. Seddon, Chem. Soc. Rev., 22, 397 (1997).

10. C.B. Aakeroy, Acta Crystallogr. B, 53, 569 (1997).

11. U. Rychlewska and R. Warzajtis, Acta Crystallogr. B, 56, 833 (2000).

12. K. Rajagopal, M. Subha Nandhini, R.V. Krishnakumar and S. Natarajan, Acta Crystallogr. Sect. E Struct. Rep. Online, 58, o1306 (2002).

13. S.A.M. Britto Dhas and S. Natarajan, Cryst. Res. Technol., 42, 471 (2007).

14. M.K. Marchewka, J. Baran, A. Pietraszko, A. Haznar, S. Debrus and H. Ratajczak, Solid State Sci., 5, 509 (2003).

15. M.K. Marchewka, H. Ratajczak and S. Debrus, Opt. Phys., 12, 113 (2003).

16. J. Shen, J. Zheng, Y. Che and B. Xi, J. Cryst. Growth, 257, 136 (2003).

17. V. Subhashini, S. Ponnusamy and C. Muthamizhchelvan, Spectrochim. Acta A, 87, 265 (2012).

18. M.-L. Liu, Acta Cryst Sect. E, 68, o289 (2012).

19. R. Sankar, C.M. Raghavan, M. Balaji, R.M. Kumar and R. Jayavel, Cryst. Growth Des., 7, 348 (2007).

20. A. Ashour, N. El-Kadry and S.A. Mahmoud, Thin Solid Films, 269, 117 (1995).

21. G. Peramaiyan, P. Pandi, B.M. Sornamurthy, G. Bhagavannarayana and R. Mohan Kumar, Spectrochim. Acta A, 95, 310 (2012).

22. P. Pandi, G. Peramaiyan, S. Sudhahar, G. Chakkaravarthi, R. Mohan Kumar, G. Bhagavannarayana and R. Jayavel, Spectrochim. Acta A, 98, 7 (2012).

23. S. Gowri, T. Uma Devi, D. Sajan, A. Chandramohan and N. Lawrence, Optik, 124, 2393 (2013).

24. K. Boopathi, P. Rajesh and P. Ramasamy, Mater. Res. Bull., 47, 2299 (2012).

25. G. Anandha Babu, G. Bhagavannarayana and P. Ramasamy, J. Cryst. Growth, 310, 2820 (2008).

26. J.M. Linet and S.J. Das, Physica B, 405, 3955 (2010).

27. K. Sangwal, M. Hordyjewicz and B. Surowska, J. Optoelectron. Adv. Mater., 4, 875 (2002).

28. K. Sangwal, A. Kothari and S.K. Arora, Surf. Sci., 600, 1475 (2006).

29. E. Meyer and Z. Ver, Dtsch. Ing., 52, 645 (1908).

30. E.M. Onitsch, Mikroskopie, 95, 12 (1950).

31. S.K. Kurtz and T.T. Perry, J. Appl. Phys., 39, 3798 (1968). 